\title{
Variant Hemoglobin Spectrum By Cation Exchange High Performance Liquid Chromatography: A Study of 2035 Subjects
}

\author{
Ankur N. Sarvaiya, Sanjaykumar C. Chauhan* \\ Dept. of Pathology, GMERS Medical College, Himmatnagar, Gujarat, India
}

\begin{abstract}
Introduction: Hemoglobinopathies and thalassemia are hereditary disorders of hemoglobin (Hb) affecting mankind at prevalent regional level. Automated cation exchange high performance liquid chromatography is being increasingly used as the initial diagnostic method for identifying normal and abnormal hemoglobin variants.

Methodology: Total 2035 sample received and studied. All samples run on cation exchange high performance liquid chromatography machine by BIO-RAD.

Results: Total 386(18.96\%) cases had abnormal hemoglobin fractions. Beta thalassemia major cases were $17(0.83 \%)$. Beta thalassemia intermedia cases were $4(0.19 \%)$. Sickle cell trait (heterozygous Hb S) cases were $96(4.71 \%)$. Double heterozygous for sickle cell-beta thalassemia cases were $14(0.68 \%)$. There were 06 cases $(0.29 \%)$ of $\mathrm{Hb}$ D heterozygous. There were one each case of Hb E heterozygous and $\mathrm{Hb}$ E-beta thalassemia $(0.04 \%$ each). $\mathrm{Hb} \mathrm{F}$ was raised in 7 adult cases $(0.34 \%)$.

Conclusion: To conclude, cation exchange high performance liquid chromatography is less time consuming, cost effective, labor saving, reproducible, accurate, sensitive and specific method to detect hemoglobinopathies and thalassemia. Most of the abnormal cases are diagnosed with this method, with few inconclusive cases require further genetic and molecular workup.
\end{abstract}

Keywords: Haemoglobinopathies, Thalassemia, Cation Exchange High Performance Liquid Chromatography, Screening

\section{Introduction}

Hemoglobin $(\mathrm{Hb})$ is a conjugated protein of molecular weight 64,000 . Haem group is attached to two pairs of polypeptide globin chains. Haem group binding with each of these chains is important for oxygen carrying capacity of hemoglobin and also it stabilizes the hemoglobin molecule. There are also many naturally occurring variants of hemoglobin (more than 1000) which are genetically determined, most are harmless and some of them have serious clinical consequences ${ }^{[1]}$. Hereditary disorders of hemoglobin result either from qualitative defect (structural alteration of a globin polypeptide chain) or quantitative defect(reduced synthesis of globin polypeptide chain). Examples of qualitative defects are $\mathrm{Hb} \mathrm{S}, \mathrm{Hb} \mathrm{D}$ and $\mathrm{Hb}$ E etc. Examples of quantitative defects are alpha and beta thalassemia. Major causes of morbidity of all these are homozygous beta thalassemia and some alpha thalassemia [2]. $5 \%$ of world population is a carrier for hemoglobin disorders as per world health organization report ${ }^{[3]}$. In India 10,000 children every year are born suffering from thalassemia major, amounting to approximately $10 \%$ of total world numbers ${ }^{[4]}$. In India individuals with beta thalassemia are $3.5-15 \%$ in total population ${ }^{[5]}$. Almost 10 billion rupees per year is spent for thalassemia patients in India. In India still the conventional methods are used in most of the places for diagnosing these defects. These conventional methods are family history, clinical features, hemoglobin level, red blood cell indices, red cell count, peripheral blood smear study, $\mathrm{Hb}$ A2 quantification, $\mathrm{Hb} \mathrm{F}$ quantification, cellulose acetate electrophoresis at alkaline $\mathrm{pH}$ for hemoglobin and sickling test. Various drawbacks and shortcomings of these methods are that $\mathrm{Hb}$ S, G,D,Q and Lepore have same mobility on electrophoresis and $\mathrm{Hb} \mathrm{A}, \mathrm{C}$ and $\mathrm{E}$ also have same mobility ${ }^{[6]}$. Double heterozygous states also are difficult to diagnose ${ }^{[6]}$. Clinical and laboratory features have low specificity.

Parents with various heterozygous states can lead to offspring with double heterozygous or homozygous defects. Automated cation exchange high performance liquid chromatography is being increasingly used as the initial diagnostic method for identifying various normal and abnormal hemoglobin ${ }^{[7,8]}$. It is simple, easy, reliable, accurate yet cost effective method for early detection of normal and abnormal hemoglobin ${ }^{[9,10]}$.

\section{Material \& Methods}

Total 2035 sample received and studied from January 2015 to August 2016 that were sent for hemoglobin variant analysis 
in a tertiary care center in north Gujarat. Most of the cases were from North gujarat and Kutch area of Gujarat with some were from Rajasthan, Madhya Pradesh, Uttarpradesh and Bihar. Naked eye single tube red cell osmotic fragility test was done and observed for hemolysis. All the samples were run by automated hematology analyzer (cellenium trivitron, abacus3 and abacus5) and hemoglobin values and red cell indices were noted. The whole blood samples were taken in K3 EDTA (Ethylene Diamine Tetraacetic Acid) anticoagulant containing vacutte. Anticoagulated whole blood samples were analyzed with BIO-RAD VARIANT II (beta thalassemia short program) machine by BIORAD laboratories, United States of America. It runs on cation exchange high performance liquid chromatography principle. On each run, one calibrator and two controls with one blank were added initially. Acceptable area was between 1-3 million. Ranges outside this area had been rejected. All the data regarding clinical history, history of blood transfusion were recorded. Chromatogram results of samples printed. Specific defined windows are there from manufacturer from specific retention time and integrated peaks are accordingly assigned [11]. The retention time is the time taken from the sample injection up to the apex of elution peak ${ }^{[11]}$. Established ranges of elution of common hemoglobin variants are marked as "windows" (Table 1). Chromatogram result shows retention time, area, area percentage and concentration. Retention time not assigned comes as an unknown. Each sample takes somewhat around 6 minutes for result.

\section{Results}

Total 2035 samples received. Out of which 1186(58.28\%) were male and $849(41.72 \%)$ were female. The overall sample patients age range was from 28 days to 74 years. The few upper age range was mostly grandparents of patients for parental screening. Total 386(18.96\%) cases had abnormal hemoglobin fractions. Most common defect was increased $\mathrm{Hb}$ A2. 3.9\% was taken as a cutoff for beta thalassemia trait diagnosis (BTT). Total 216 cases were diagnosed with beta thalassemia trait (raised HbA2). Peripheral blood smear findings were microcytic hypochromic red blood cells, anisocytosis, and target cells. Red blood cell count is increase in most cases. The $\mathrm{Hb}$ A2 retention time was between 3.50 to $3.75 \mathrm{~min}$. Table 1 shows retention times for all predefined windows. Mentzer index was less than 13 in 179 out of 216 cases. Mentzer index is a ratio of mean corpuscular volume in $\mathrm{fL}$ divided by the red blood cell count in Millions per micro Liter.

Beta thalassemia major cases were $17(0.83 \%)$. Beta thalassemia intermedia cases were $4(0.19 \%)$. All the thalassemia major cases were first presented in their first two years. Peripheral blood smear findings of these cases were severe anemia, severely microcytic and hypochromic red blood cells, moderate to severe anisopoikilocytosis, target cells and nucleated red blood cells.

Sickle cell anemia (homozygous $\mathrm{Hb} \mathrm{S}$ ) patients had $\mathrm{Hb} \mathrm{S}$ range from $72-89 \%$ and total $19(0.93 \%)$ cases were there. Sickle cell trait (heterozygous $\mathrm{Hb} \mathrm{S}$ ) cases were 96(4.71\%). $\mathrm{Hb} \mathrm{S}$ in them was from 32 to $38 \%$. Double heterozygous for sickle cell-beta thalassemia cases were 14(0.68\%).

There were 06 cases $(0.29 \%)$ of $\mathrm{Hb} \mathrm{D}$ heterozygous. $\mathrm{D}$ window is displayed in HPLC. Retention time was between 4.03 to $4.21 \mathrm{~min}$. There were one each case of $\mathrm{Hb} \mathrm{E}$ heterozygous and $\mathrm{Hb}$ E-beta thalassemia $(0.04 \%$ each). There is a peak of $\mathrm{Hb} \mathrm{E}$ in $\mathrm{A} 2$ region. Retention time was $3.58 \mathrm{~min}$. $\mathrm{Hb} \mathrm{F}$ was raised in 7 adult cases $(0.34 \%)$. Provisional diagnosis of hereditary persistence of fetal $\mathrm{Hb}$ was made in each case with an advice for molecular confirmation. Various abnormal hemoglobin defects in our study are shown in table 2 and figure 1. Various hematological parameters are shown in table 3.

Table 1: Window time and retention time of predefined parameters of BIO-RAD VARIANT II.

\begin{tabular}{|c|c|c|}
\hline Peak name & Window(min) & Retention time(min) \\
\hline F window & $1.00-1.30$ & 1.15 \\
\hline P2 window & 1.45 \\
\hline P3 window & 1.75 \\
\hline A window & $1.60-1.90$ & 2.60 \\
\hline A2 window & $1.90-3.30$ & 3.60 \\
\hline D window & $3.30-3.90$ & 4.10 \\
\hline S window & $3.90-4.30$ & 4.50 \\
\hline C window & $4.30-4.70$ & 5.10 \\
\hline
\end{tabular}

${ }^{*} \mathrm{P} 2$ and P3 are associated with $\mathrm{Hb} \mathrm{A}$ 
Table 2: Sex wise distribution of hemoglobinopathies.

\begin{tabular}{|l|c|c|c|}
\hline Hemoglobinopathies & Male & Female & Total (percentage) \\
\hline Beta thalessemia trait & 119 & 97 & $216(10.61 \%)$ \\
\hline Beta thalassemia major & 11 & 06 & $17(0.83 \%)$ \\
\hline Thalassemia intermedia & 01 & 12 & $19(0.93 \%)$ \\
\hline Hb S homozygous & 07 & 51 & $96(4.71 \%)$ \\
\hline Hb S heterozygous & 45 & 06 & $14(0.68 \%)$ \\
\hline Hb S- beta thalassemia & 08 & 02 & $06(0.29 \%)$ \\
\hline Hb D heterozygous & 04 & 00 & $01(0.04 \%)$ \\
\hline Hb E heterozygous & 01 & 00 & $02(0.09 \%)$ \\
\hline Hb D-beta thalassemia & 02 & 00 & $01(0.04 \%)$ \\
\hline HbS-Hb D & 01 & 00 & $01(0.04 \%)$ \\
\hline Hb D-Hb E & 01 & 01 & $01(0.04 \%)$ \\
\hline Hb E-beta thallesemia & 00 & 04 & $07(0.34 \%)$ \\
\hline HPFH & 03 & 183 & $386(18.96 \%)$ \\
\hline TOTAL & 203 & 03 & \\
\hline
\end{tabular}

Table 3: Hematological parameters of normal and different hemoglobinopathies.

\begin{tabular}{|c|c|c|c|c|c|c|c|c|}
\hline Parameter & Normal & BTT & Thal major & $\begin{array}{c}\text { Hb S } \\
\text { Homo. }\end{array}$ & $\begin{array}{c}\text { Hb S } \\
\text { Hetero. }\end{array}$ & $\begin{array}{c}\text { Sickle- } \beta \\
\text { thal }\end{array}$ & $\begin{array}{c}\text { Hb D } \\
\text { hetero. }\end{array}$ & HPFH \\
\hline $\mathrm{Hb}(\mathrm{g} / \mathrm{dl})$ & $10.6 \pm 2.9$ & $10.2 \pm 2.4$ & $4.86 \pm 2.23$ & $6.38 \pm 2.1$ & $10.1 \pm 2.9$ & $7.68 \pm 2.3$ & $10.9 \pm 2.9$ & $12.3 \pm 2.8$ \\
\hline RBC & $4.55 \pm 0.9$ & $5.62 \pm 0.82$ & $2.36 \pm 1.32$ & $3.26 \pm 0.8$ & $4.2 \pm 0.36$ & $3.86 \pm 1.0$ & $4.7 \pm 1.25$ & $4.6 \pm 0.9$ \\
\hline PCV & $31.4 \pm 4.7$ & $30.4 \pm 3.62$ & $15.2 \pm 2.91$ & $21.2 \pm 5.23$ & $30.6 \pm 7.1$ & $24.1 \pm 7.3$ & $35.9 \pm 10.8$ & $39.1 \pm 4.5$ \\
\hline MCV & $76.7 \pm 12.71$ & $59.91 \pm 7.1$ & $61.9 \pm 7.2$ & $76.1 \pm 8.6$ & $70.6 \pm 5.1$ & $70.4 \pm 6.34$ & $75.5 \pm 20.4$ & $81.1 \pm 7.5$ \\
\hline $\mathrm{MCH}$ & $26.4 \pm 3.85$ & $20.3 \pm 2.58$ & $21.62 \pm 4.2$ & $24.7 \pm 3.2$ & $21.6 \pm 4.0$ & $23.4 \pm 2.1$ & $24.7 \pm 4.1$ & $25.6 \pm 3.4$ \\
\hline $\mathrm{MCHC}$ & $31.21 \pm 2.1$ & $30.4 \pm 1.98$ & $31.1 \pm 4.62$ & $31.8 \pm 2.3$ & $30.9 \pm 2.3$ & $32.4 \pm 1.4$ & $32.4 \pm 2.4$ & $31.5 \pm 2.3$ \\
\hline RDW-CV & $18 \pm 4.7$ & $18.4 \pm 3.8$ & $20.32 \pm 5.2$ & $22.5 \pm 4.1$ & $21.6 \pm 4.3$ & $21.68 \pm 3.9$ & $18.4 \pm 3.64$ & $17.6 \pm 2.8$ \\
\hline $\mathrm{Hb} \mathrm{A}$ & $89.12 \pm 4.65$ & $86.3 \pm 4.3$ & $20.4 \pm 19.8$ & $5.4 \pm 2.3$ & $58.1 \pm 4.3$ & $6.3 \pm 2.21$ & $51.68 \pm 5.27$ & $85.2 \pm 3.5$ \\
\hline $\mathrm{Hb}$ A2 & $2.63 \pm 0.61$ & $5.15 \pm 0.72$ & $3.4 \pm 1.2$ & $3.54 \pm 0.86$ & $3.4 \pm 0.9$ & $5.58 \pm 1.21$ & $2.4 \pm 0.38$ & $2.7 \pm 0.51$ \\
\hline $\mathrm{Hb} F$ & $0.65 \pm 0.36$ & $1.4 \pm 0.5$ & $81.2 \pm 14.3$ & $15.9 \pm 6.89$ & $1.9 \pm 3.21$ & $2.31 \pm 7.4$ & $0.7 \pm 0.2$ & $9.4 \pm 3.4$ \\
\hline $\mathrm{Hb} \mathrm{S}$ & - & - & - & $74.5 \pm 8.4$ & $32.6 \pm 5.6$ & $69.4 \pm 8.93$ & - & - \\
\hline $\mathrm{Hb} \mathrm{D}$ & - & - & - & - & - & - & $36.7 \pm 6.8$ & - \\
\hline
\end{tabular}

*Numbers are mean \pm standard deviation. $H b=$ hemoglobin, $R B C=$ red cell count, $P C V=$ packed cell volume, MCV= mean corpuscular volume, $M C H=$ mean corpuscular hemoglobin, $M C H C=$ mean corpuscular hemoglobin concentration, $R D W=$ red cell distribution width, BTT= beta thalassemia trait, Thal major= beta thalassemia major, Homo=homozygous, Hetero=heterozygous, HPFH=hereditary persistence of fetal hemoglobin 
Fig. 1: Column chart shows frequency of hemoglobinopathies.

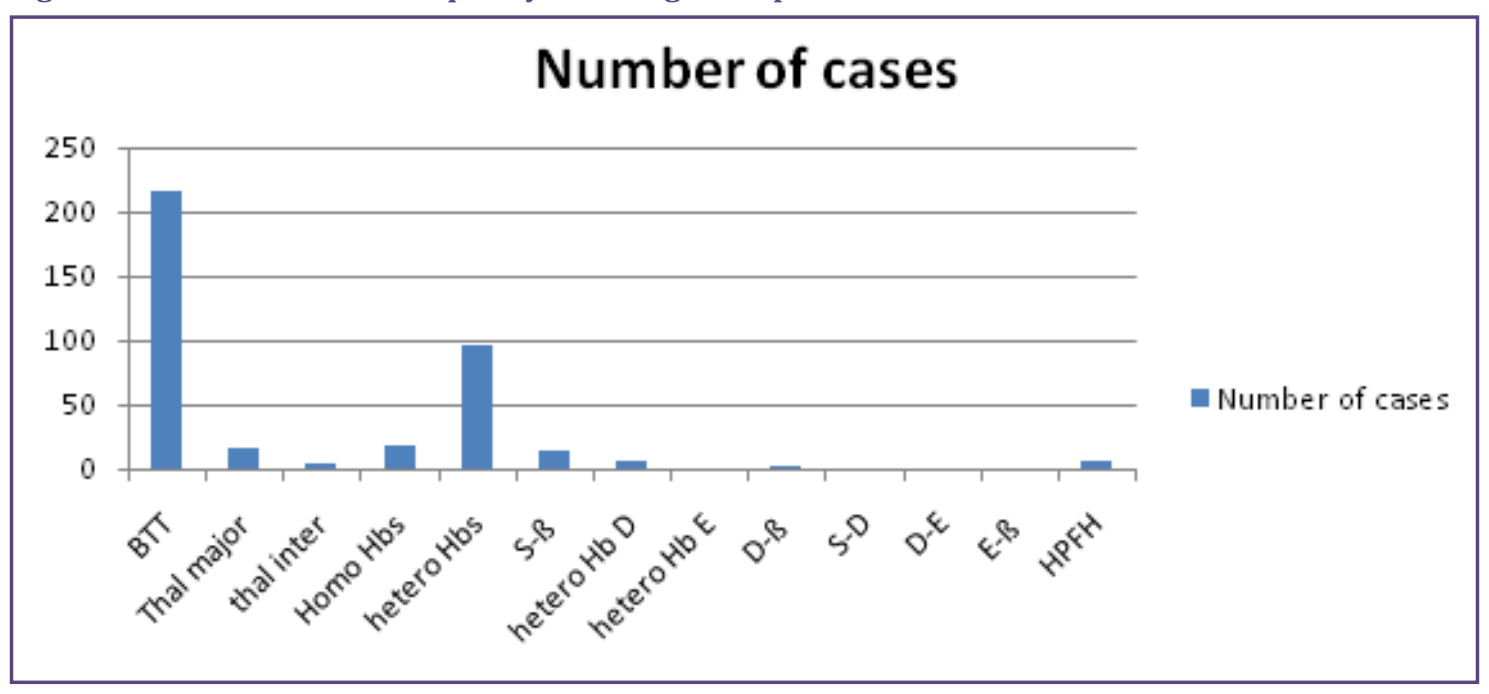

*BTT $=$ beta thalassemia trait, Thal major = beta thalassemia major, thal inter $=$ thalassemia intermedia, Homo=homozygous, Hetero=heterozygous, $s$ - $\beta=$ sickle cell beta thalassemia, $D-\beta=H b$ Deta thallesemia, $S-D=$ sickle cell $H b D, D-E=H b D H b E, E-\beta=H b$ E beta thalessemia, HPFH=hereditary persistence of fetal hemoglobin

\section{Discussion}

In India and Mediterranean belt, still thalassemias and hemoglobinopathies are very common causes of morbidity and also exert burden on expenditure. To reduce the burden accurate and reliable screening procedure should be there. The diagnosis of hemoglobinopathies and thalassemia is required to explain hematological abnormalities, identify abnormality in pre symptomatic period, preconceptional screening, screening of fetus to offer termination of pregnancy, and to confirm a presumptive diagnosis ${ }^{[12]}$.

Naked eye single tube red cell osmotic fragility (NESTROFT) and red cell indices are helpful tests that aid in diagnosis but the result must have been supported by confirmatory test as suggested by Chakrabarti et al ${ }^{[13]}$, Gorakshakar et al ${ }^{[14]}$, Dangi et al ${ }^{[15]}$ and other studies ${ }^{[16]}$. Yousafzai et al stated that NESTROFT is easy and simple but it is very much error prone, red cell indices also are lacking in sensitivity and specificity ${ }^{[16]}$. We have found in our study that sensitivity and specificity of mentzer index are 60.4 and $91 \%$. Both of these are lacking in sensitivity and specificity so not used for diagnostic purpose exclusively.

So far, some of the common investigations done for thalassemia and hemoglobinopathies are Hb electrophoresis by cellulose acetate at alkaline $\mathrm{pH}$, acid electrophoresis, $\mathrm{Hb} \mathrm{F}$ quantification by alkali denaturation and $\mathrm{Hb} \mathrm{A} 2$ quantification by chromatography. These all methods have certain limitations; these methods are totally dependent on the performer's expertise. So variability of the result is there. Even with the same performer, the bands are not exactly positioned on the same area (reproducibility is low). To differentiate between hemoglobins that have same electrophoretic mobility is difficult and the control with known variant hemoglobin or multiple stored known controls is required to be run every time with patient's sample. It is very difficult to get a single control for comparison with all the variant hemoglobin in it ${ }^{[17]}$. It is also nearly impossible to run many samples in a single run. These methods are also time consuming. Compound heterozygous or double heterozygous states and unusual hemoglobin variants are all clinically important to diagnose, so exact identification of them is very important ${ }^{[18,19]}$. With single electrophoretic method none out of these variants can be identified precisely ${ }^{[20]}$. Cation exchange high performance liquid chromatography has high sensitivity, specificity and also is reproducible compared to hemoglobin electrophoresis ${ }^{[21]}$.

Total 386 cases $(18.96 \%)$ were diagnosed with some hemoglobin variants. Out of which beta thalassemia trait cases were $216(10.61 \%)$. This proves antenatal screening of value to prevent potential offspring with thalassemia major. Borderline $\mathrm{Hb} \mathrm{A} 2$ requires further investigation before reaching out on conclusion. Studies have suggested both iron deficiency anemia and megaloblastic anemia may have an effect on level of Hb A2; iron deficiency anemia can mildly reduce and megaloblastic anemia can mildly increase ${ }^{[22,23,24,25]}$.

Different studies by Sachdev et al ${ }^{[26]}$, Rao et al ${ }^{[27]}$, Dolai et al ${ }^{[28]}$ and Mukhopadhyay et al ${ }^{[29]}$ have taken 2600 , 800,35413 and 10407 cases respectively for their study. 
Sachdev et al [26], Jain et al ${ }^{[30]}$ and Mukhopadhyay et al [29] found $12.57 \%, 29.3 \%$ and $14.5 \%$ abnormal hemoglobin fractions respectively. Sachdev et al ${ }^{[26]}$, Rao et al [27], Dolai et al ${ }^{[28]}$ and Mukhopadhyay et al ${ }^{[29]}$ found beta thalassemia trait cases to be $8.9 \%, 18.1 \%, 10.38 \%$ and $5.6 \%$ respectively. Our findings are comparable to these different Indian studies.

\section{Conclusion}

To conclude, cation exchange high performance liquid chromatography is less time consuming, cost effective, labor saving, reproducible, accurate, sensitive and specific method to detect hemoglobinopathies and thalassemia. It should be used as a screening tool. Most of the abnormal cases are diagnosed with this method; with few inconclusive cases require genetic and molecular studies.

\section{References}

1. Hardison R, Miller W. (Updated) Globin gene server. Available at: www.globin.cse.psu.edu.

2. Kutlar F. Diagnostic approach to hemoglobinopathies. Hemoglobin. 2007 Jan 1;31(2):243-50.

3. WHO executive board EB118/5, 118th Session Report by the Secretariat on Thalassaemia and other haemoglobinopathies: Prevalence of Haemoglobinopathies. 11 May 2006:1-8.

4. Varawalla NY, Old JM, Sarkar R, Venkatesan R, Weatherall DJ. The spectrum of $\beta \square$ thalassaemia mutations on the Indian subcontinent: the basis for prenatal diagnosis. British journal of haematology. 1991 Jun 1;78(2):242-7.

5. Balgir RS. The genetic burden of hemoglobinopathies with special reference to community health in India and the challenges ahead. Indian J Hematol Blood Transfus. 2002;20(1):2-7.

6. Gupta PK, Kumar H, Kumar S, Jaiprakash M. Cation exchange high performance liquid chromatography for diagnosis of haemoglobinopathies. Medical Journal Armed Forces India. 2009 Jan 31;65(1):33-7.

7. Wild BJ, Stephens AD. The use of automated HPLC to detect and quantitate haemoglobins. International Journal of Laboratory Hematology. 1997 Sep 1;19(3):171-6.

8. Higgins TN, Ridley B. Tentative identification of hemoglobin variants in the Bio-Rad VARIANT II Hb A 1C method. Clinical biochemistry. 2005 Mar 31;38(3):272-7.

9. Phelan L, Bain BJ, Roper D, Jury C, Bain K. An analysis of relative costs and potential benefits of different policies for antenatal screening for beta thalassaemia trait and variant haemoglobins. Journal of clinical pathology. 1999;52(9):697-700.

10. Riou J, Godart C, Hurtrel D, Mathis M, Bimet C, BardakdjianMichau J, Préhu C, Wajcman H, Galactéros F. Cationexchange HPLC evaluated for presumptive identification of hemoglobin variants. Clinical chemistry. 1997;43(1):34-9.

11. Bio-Rad VARIANT II, beta thalassemia short program. Instruction Manual. 2003:10.
12. Working Party of the General Haematology Task Force of the British Committee for Standards in Haemotology. Guideline: The laboratory diagnosis of haemoglobinopathies. British Journal of Haematology. 1998;101:783-92.

13. Chakrabarti I, Sinha SK, Ghosh N, Goswami BK. BetaThalassemia Carrier Detection by NESTROFT: An Answer in Rural Scenario?. Iranian Journal of Pathology. 2012 Jan $1 ; 7(1): 19-26$.

14. Gorakshakar AC, Colah RB. Is RBC discrimination index suitable for differentiating between $\alpha$-and $\beta$-thalassemias? Indian journal of human genetics. 2011 Sep 1;17(3):115.

15. Dangi CB, Sajid M, Sawke GK, Ambhore J. Sickle cell hemoglobinopathies in district Bhopal. Indian journal of human genetics. 2010 May 1;16(2):100.

16. Yousafzai YM, Khan S, Raziq F. Beta-thalassaemia trait: Haematological parameters. J Ayub Med Coll Abbottabad. 2010;22:84-6.

17. Joutovsky A, Hadzi-Nesic J, Nardi MA. HPLC retention time as a diagnostic tool for hemoglobin variants and hemoglobinopathies: a study of 60000 samples in a clinical diagnostic laboratory. Clinical chemistry. 2004 Oct 1;50(10):1736-47.

18. Somervaille T. Disorders of Hemoglobin: Genetics, Pathophysiology, and Clinical Management. Journal of the Royal Society of Medicine. 2001; 94(11):602-603.

19. Dash S, Huisman TH. Hb [A. sub. 2] in subjects with Hb D. Clinical chemistry. 1998 Nov 1;44(11):2381-3.

20. Bain BJ. Haemoglobinopathy diagnosis. 2nd ed. Oxford: Blackwell Publishing Ltd; 2006.

21. Ou CN, Rognerud CL. Diagnosis of hemoglobinopathies: electrophoresis vs. HPLC. Clinica chimica acta. 2001 Nov 30;313(1):187-94.

22. El-Agouza I, Abu Shahla A, Sirdah M. The effect of iron deficiency anaemia on the levels of haemoglobin subtypes: possible consequences for clinical diagnosis. Clinical \& laboratory haematology. 2002 Oct 1;24(5):285-9.

23. Madan N, Sikka M, Sharma S, Rusia U. Haematological parameters and $\mathrm{HbA} 2$ levels in beta-thalassaemia trait with coincident iron deficiency. Indian journal of pathology \& microbiology. 1998 Jul;41(3):309-13.

24. Bencaiova G, Burkhardt T, Krafft A, Zimmermann R. Screening for $\beta$-thalassaemia trait in anaemic pregnant women. Gynecologic and obstetric investigation. 2006 Mar 1;62(1):20-7.

25. Gupta AD. Abrogation of macrocytosis in pernicious anemia by $\beta$-thalassemia does not mask the diagnosis of vitamin B12 deficiency. American journal of hematology. 2002 Sep 1;71(1):61-2.

26. Sachdev R, Dam AR, Tyagi G. Detection of $\mathrm{Hb}$ variants and hemoglobinopathies in Indian population using HPLC: 
report of 2600 cases. Indian journal of pathology and microbiology. 2010 Jan 1;53(1):57.

27. Rao S, Kar R, Gupta SK, Chopra A, Saxena R. Spectrum of haemoglobinopathies diagnosed by cation exchange-HPLC $\&$ modulating effects of nutritional deficiency anaemias from north India. Indian Journal of Medical Research. 2010 Nov 1;132(5):513.

28. Dolai TK, Dutta S, Bhattacharyya M, Ghosh MK. Prevalence of hemoglobinopathies in rural Bengal, India. Hemoglobin. 2012 Feb 1;36(1):57-63.
29. Mukhopadhyay D, Saha K, Sengupta M, Mitra S, Datta C, Mitra PK. Spectrum of hemoglobinopathies in West Bengal, India: a CE-HPLC Study on 10407 subjects. Indian Journal of Hematology and Blood Transfusion. 2015 Mar 1;31(1):98-103.

30. Jain BB, Roy RN, Ghosh S, Ghosh T, Banerjee U, Bhattacharya SK. Screening for thalassemia and other hemoglobinopathies in a tertiary care hospital of West Bengal: implications for population screening. Indian journal of public health. 2012 Oct 1;56(4):297.

*Corresponding author:

Dr. Sanjaykumar C. Chauhan, Dept. of pathology, GMERS Medical College, Himmatnagar, Gujarat, India

Phone: +91 09687626937

Email: drsanjaychauhan@gmail.com

Date of Submission : 06.03.2017

Date of Acceptance : 31.03.2017

Financial or other Competing Interests: None.

Date of Publication : 04.07.2017 